REVIEW

\title{
Systemic lactose intolerance: a new perspective on an old problem
}

\author{
S B Matthews, J P Waud, A G Roberts, A K Campbell
}

Postgrad Med J 2005;81:167-173. doi: 10.1136/pgmi.2004.025551

Intolerance to certain foods can cause a range of gut and systemic symptoms. The possibility that these can be caused by lactose has been missed because of "hidden" lactose added to many foods and drinks inadequately labelled, confusing diagnosis based on dietary removal of dairy foods. Two polymorphisms, $C / T_{13910}$ and $G / A_{22018}$, linked to hypolactasia, correlate with breath hydrogen and symptoms after lactose. This, with a 48 hour record of gut and systemic symptoms and a six hour breath hydrogen test, provides a new approach to the clinical management of lactose intolerance. The key is the prolonged effect of dietary removal of lactose. Patients diagnosed as lactose intolerant must be advised of "risk" foods, inadequately labelled, including processed meats, bread, cake mixes, soft drinks, and lagers. This review highlights the wide range of systemic symptoms caused by lactose intolerance. This has important implications for the management of irritable bowel syndrome, and for doctors of many specialties.

See end of article for authors' affiliations

Correspondence to: Professor A K Campbell, Department of Medical Biochemistry and Immunology, Wales College of Medicine, Cardiff University, Heath Park, Cardiff CF14 4XN UK; campbellak@cf.ac.uk

Submitted 15 June 2004 Accepted

22 September 2004
A 53 year old woman with severe irritable bowel syndrome (IBS), eczema, asthma, and osteoarthritis was investigated for lactose intolerance (see below). This diagnosis has transformed her life. She has been essentially symptom free and off all medication for over two years. Similar dramatic stories have been repeated among 300 patients we have diagnosed with systemic lactose intolerance.

\section{AN UNUSUAL CASE?}

This 53 year old woman had a 10 year history of asthma, eczema and sinus problems, muscle and joint pain, and lack of concentration. This was so severe that she was worried that she was developing Alzheimer's disease. From childhood she complained of an itchy rash and eczema, frequent diarrhoea, nausea, and sickness. She had been diagnosed as having eczema, asthma, and osteoarthritis, and was awaiting a knee replacement operation. She was taking a range of medications, including skin creams, antihistamines, asthma inhalers, antibiotics, antidiarrhoeals, and strong pain relief. We carried out a lactose intolerance test $(50 \mathrm{~g}$ oral lactose folthree hours) (fig 1). By three hours her breath hydrogen had not risen to $>20 \mathrm{ppm}$ over the nadir, the recognised level for diagnosing lactose lowed by an analysis of breath hydrogen for intolerance. However, she recorded a range of gut and systemic symptoms after ingestion of lactose. These included abdominal pain, diarrhoea, nausea and vomiting, headache, light headedness, feeling drunk, heart palpitations, joint and muscle pain. These symptoms after lactose lasted severely for three days. She was advised to remove all lactose from her diet for one month. This entailed not only avoidance of food and drinks containing "dairy" products, but she was advised also to avoid foods and drinks where lactose can be added in large quantities without being on the label. Within one month she described her skin as "wonderful". Her asthma and sinusitis had gone, and her joints were much improved, her diarrhoea and abdominal pain gone. She no longer needed any medication and was taken off the list for a knee replacement.

A DNA test ${ }^{1}$ now provides a vital aid to diagnosis. Intolerance to certain foods can cause a range of gut and systemic symptoms. ${ }^{2}$ The possibility that these are caused by lactose has been missed because of "hidden" lactose added to many foods and drinks without being on the label is not generally realised, confusing diagnosis based on dietary removal of dairy foods. ${ }^{3}$ An important change in the clinical management of lactose intolerance and IBS is now required.

\section{LACTOSE AND LACTASE}

Lactose, $\beta$ galactose 1,4 glucose, is the unique sugar in the milk of all mammals, ${ }^{3-5}$ except Pinnepedia (sea lions and walruses). It is hydrolysed in the small intestine by the enzyme lactase. All mammals, except white northern Europeans and some other ethnic groups (for example, the Bedouins and African dairying tribes), are hypolactasic - that is, they have a low lactase. This is because they lose $75 \%-90 \%$ of the enzyme within a few years of weaning. ${ }^{3-11}$ The molecular mechanism causing this is unknown. It is not attributable to polymorphisms within the lactase gene itself or within its promoter $(55 \mathrm{~kb}$ within $70 \mathrm{~kb}$, long arm of chromosome 2 (2p.2lq) 17 exons $\left.^{8}\right)$. However, there is a close correlation between lactase persistence and two polymorphisms, $\mathrm{C} / \mathrm{T}_{13910}$ and $G / A_{22018}$ upstream from the lactase gene ${ }^{18}$, CC/GG being associated with lactase non-persistence and lactose intolerance.

The eventual level and time course of loss of lactase vary considerably with ethnic group..$^{6-8}$ Chinese and Japanese lose $80 \%-90 \%$ within three to four years after weaning, whereas Asians and Jews can retain some 20\%-30\%, taking several years to reach the lowest level. The 


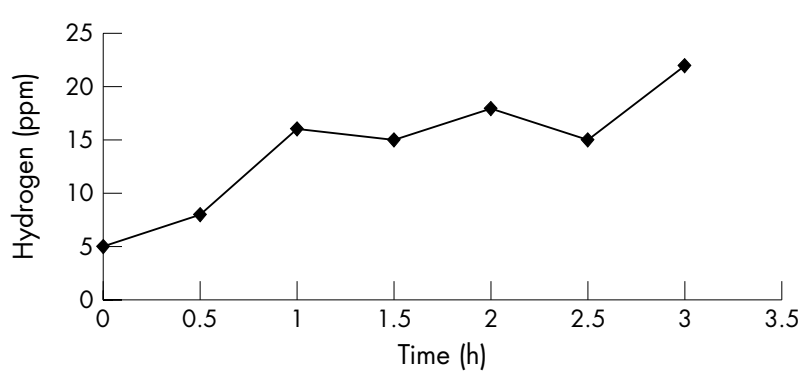

Figure 1 Breath hydrogen analysis of the female case report. Breath hydrogen was monitored using a hand held detector (Bedfont, UK) every 30 minutes for three hours after the ingestion of $50 \mathrm{~g}$ oral lactose.

$10 \%$ of white northern Europeans who lose lactase after weaning can take 18-20 years to reach their nadir. Thus most of the world's adult population (about 6000 million people) are hypolactasic.

\section{LACTOSE INTOLERANCE}

It is important to distinguish between hypolactasia, a low level of lactase, and clinical lactose intolerance. Lactose intolerance was first described by Hippocrates. But only in the past 50 years has this condition been recognised and diagnosed medically. ${ }^{30-15}$ Lactose intolerance is defined as gut pain and distension, borborygmi, flatus, and diarrhoea (table 1A), induced by lactose..$^{3-4}$ It is caused by hypolactasia. But lactose intolerance also causes nausea and vomiting, with many patients presenting with constipation because of reduced intestinal motility rather than diarrhoea. Lactose also causes a range of systemic symptoms (table 1B), including headaches and light headedness, loss of concentration, difficulty with short term memory, severe tiredness, muscle and joint pain, various allergies, heart arrhythmia, mouth ulcers, sore throat, and increased frequency of micturition. ${ }^{316-20}$ These have been missed because of the spasmodic nature of the symptoms, the prevalence of any one symptom varying from $20 \%$ to $100 \%$ (table 1B). Yet removal of lactose from the diet can transform the life of someone with lactose intolerance, often after years of discomfort and misdiagnosis, including accusations of psychosomatic illness. Lactose intolerance causes great distress in many patients, who often do not realise that lactose is added to many foods and drinks, in addition to those directly from milk and its products without stating this on the label. The occurrence of this "hidden" lactose is not widely known to clinicians or dietitians, and may explain undiagnosed cases of food intolerance. ${ }^{2}$ When the dairy exclusion diet apparently fails lactose intolerance is often ruled out inappropriately. The current diagnosis of lactose intolerance entails taking $50 \mathrm{~g}$ of lactose orally, equivalent to one litre of cows' milk, followed by measurement of breath hydrogen every 30 minutes for three hours. ${ }^{3} 12132122$ A breath hydrogen of 20 ppm above the nadir indicates lactose intolerance. The large intake of lactose overloads the lactase left in those who lose it after weaning, and inevitably leads to symptoms. However, the occurrence of symptoms after $50 \mathrm{~g}$ lactose does not mean that you cannot tolerate some milk. Even some control subjects, with no history of gut problems, exhibited some symptoms after 50 g lactose.

Data were based on a clinical study of 133 patients who were referrals to a food intolerance clinic. Of these $85 \%$ came from gasteroenterologists, $15 \%$ from other physicians, and $10 \%$ from primary care. Ten cases refused the dietary management or did not return for follow up. Fifteen controls were people with no relevant medical history and who took a mixed diet. The ethnic origins were mainly white northern
Table 1 Symptoms of lactose intolerance

\begin{tabular}{ll}
\hline & $\begin{array}{l}\text { Number people } \\
\text { with symptom } \\
\text { (\% of total) }\end{array}$ \\
\hline (A) Gut related & 100 \\
Abdominal pain & 100 \\
Gut distension & 100 \\
Borborygmi & 100 \\
Flatulence & 70 \\
Diarrhoea & 30 \\
Constipation & 78 \\
Nausea & 78 \\
Vomiting & \\
(B) Systemic & 86 \\
Headache and light headedness & 82 \\
Loss of concentration and poor short term memory & 63 \\
Long term severe tiredness & 71 \\
Muscle pain & 71 \\
Joint pain, and/or swelling and stiffness & 40 \\
Allergy & \\
Eczema & \\
Pruritis & \\
Rhinitis & \\
Sinusitis & \\
Asthma & \\
Heart arrhythmia & \\
Mouth ulcers & \\
Increased frequency of micturition & 24 \\
Sore throat & 30 \\
\hline & $<20$ \\
& $<20$ \\
\hline
\end{tabular}

European (89\%). Each patient was given $50 \mathrm{~g}$ ( $1 \mathrm{~g} / \mathrm{kg}$ for children) oral lactose after an overnight fast. Symptoms were recorded for 48 hours. The data in the right hand column represent the number of patients diagnosed as lactose intolerant with a particular symptom expressed as a \% of the total. Control patients with no history of gut symptoms and a negative breath hydrogen after $50 \mathrm{~g}$ oral lactose showed mostly no symptoms after the lactose load. However, a few control patients did record one or two symptoms suggesting that the $50 \mathrm{~g}$ lactose load may overload the lactase in the small intestine in those with lactase persistence after weaning.

There are five problems in the current diagnosis of lactose intolerance:

- The standard test lacks sensitivity (table 2), exacerbated by the fact that there is no recommendation that symptoms should be routinely recorded during the test. ${ }^{12}$ The long term conditions can be insufficient to generate hydrogen. ${ }^{21}$

- The test can cause severe symptoms, sometimes lasting for several days.

- Intolerance to some foods can cause IBS, with a wide range of unexplained systemic symptoms in addition to gut symptoms. ${ }^{23}$ The possibility that these are caused by lactose intolerance has been missed.

- It is not widely known that lactose is added to a large number of foods and drinks without being on the label, resulting in failure to diagnose lactose intolerance when symptoms recur even after removing dairy products from the diet. ${ }^{38-20}$

- There is no genetic test for lactose intolerance. ${ }^{1}$

We have correlated two polymorphisms, $\mathrm{C} / \mathrm{T}_{13910}$ and $\mathrm{G} / \mathrm{A}_{22018}$ (fig 2), closely associated with lactase persistence, ${ }^{123}$ with breath hydrogen, gut and systemic symptoms (table 1), induced after lactose ingestion in over 300 adults and children. DNA analysis is an important addition to the investigation of lactose intolerance, a redefinition of lactose intolerance being required. Eighty per cent of patients, 
Table 2 Sensitivity and specificity of the breath hydrogen test for lactose intolerance

\begin{tabular}{lllll}
\hline Sensitivity (\%) & $\mathbf{0 - 3}$ hours & $\mathbf{3 - 6}$ hours & $\mathbf{6 - 9}$ hours & $\mathbf{9 - 1 2}$ hours \\
\hline Total & 33.7 & 56.1 & 60.2 & 63.3 \\
CC/GG & 100 & 100 & 100 & 100 \\
CT/GA & 42 & 60 & 63 & 64 \\
TT/AA & 14 & 31 & 34 & 40 \\
\hline Specificity (\%) & & & & \\
\hline Total & 96 & 88 & 84 & 80 \\
CC/GG & 100 & 100 & 100 & 100 \\
CT/GA & 100 & 88 & 88 & 77 \\
TT/AA & 93 & 87 & 81 & 81 \\
\hline
\end{tabular}

Definitive diagnosis of lactose intolerance was based on a substantial improvement in the number and severity of symptoms after 12 weeks of complete exclusion of lactose from the diet, including hidden lactose. A breath test was positive if the breath hydrogen rose $20 \mathrm{ppm}$ over the nadir during the time interval defined after ingesting $50 \mathrm{~g}$ lactose $(1 \mathrm{~g} / \mathrm{kg}$ for children). Sensitivity $(\%)=(T P \times 100) /(T P+F N)$ where $T P+F N=$ total number of patients diagnosed clinically with lactose intolerance. Specificity $(\%)=(\mathrm{TN} \times 100) /(\mathrm{TN}+\mathrm{FP})$ where $\mathrm{TN}+\mathrm{FP}=$ total number of patients diagnosed clinically as not having lactose intolerance. True positive $(T P)=$ positive breath test in a patient diagnosed with lactose intolerance. True negative $(T N)=$ negative breath test in a patient without lactose intolerance. False positive $(\mathrm{FP})=$ positive breath test in a patient without lactose intolerance. False negative $(\mathrm{FN})=$ negative breath test in a patient diagnosed with lactose intolerance. It is also possible to then calculate the positive $(\mathrm{PV}+)$ and negative (PV-) predictive values. $(\mathrm{PV}+) \%=(\mathrm{TP} \times 100) /(\mathrm{TP}+\mathrm{FP}) ;(\mathrm{PV}-) \%=(\mathrm{TN} \times 100) /(\mathrm{TN}+\mathrm{FN})$ The optimum time was six hours with a PV+ for all patients of $95 \%$, and a PV- of $34 \%$.

referred with IBS, were lactose intolerant based on significant, persistent loss of symptoms after 12 weeks on a true lactose free diet. Eighty two per cent of those with $\mathrm{CT}_{13910} /$ $\mathrm{GA}_{22018}$ (41\% of total) and $68 \%$ of those with $\mathrm{TT}_{13910} \mathrm{AA}_{22018}$ (41\% of total) genotypes were lactose intolerant. All patients with the $\mathrm{CC}_{13910} / \mathrm{GG}_{22018}$ genotype ( $16 \%$ of total; one case $\mathrm{CC}_{13910} / \mathrm{GA}_{22018}$ ) were severely lactose intolerant having a breath hydrogen $>20 \mathrm{ppm}$ within six hours and severe clinical symptoms. Detection avoids symptoms induced by the lactose challenge. Only $45 \%$ of $\mathrm{CT}_{13910} / \mathrm{GA}_{22018}$ and $20 \%$ of $\mathrm{TT}_{13910} / \mathrm{AA}_{22018}$ had raised breath hydrogen, which should be for six hours with gut and systemic symptoms recorded for 48 hours. The breath $\mathrm{H}_{2}$ test had a $95 \%$ positive predictive value by six hours, but only a $34 \%$ negative predictive value (table 2). Definitive diagnosis requires removal of both dairy and "hidden" lactose from the diet (fig 3).

\section{THE MECHANISMS CAUSING HYPOLACTASIA AND LACTOSE INTOLERANCE}

Lactase is a unique enzyme in its formation, location and enzymatic activity. ${ }^{84-26}$ It is formed as a 1927 amino acid protein, and then processed, leaving a final protein of 1059 amino acids as a dimer of $320 \mathrm{kDa}$. Lactase (lactase phlorizinhydrolase-LPH, EC 3.2.1.62/108; note $\beta$ galactosidase is EC 3.2.1.23, mistakenly used for lactase in some publications) is highly unusual, having two active sites within one polypeptide chain, one hydrolysing lactose, the other aryl and aliphatic glycosides such as phlorizin into glucose and phloretin, the latter being a potent diabetic agent. Two important natural substrates for this latter site are cerebrosides, a crucial source of sphingosine, and glycosyl-pyridoxal, ${ }^{27}$ a vital source of vitamin B6. Lactase has no sequence similarity to its bacterial counterpart $\beta$ galactosidase. ${ }^{28}$ There are three causes of loss of lactase (hypolactasia):

- Congenital complete loss of lactase (very rare).

- Inherited loss, after weaning (common).

- Secondary intestinal damage, for example, infections such rotavirus and Giardia, or hormonal imbalance.

Only the last of these is potentially reversible, and thus important to identify clinically. The genetics of lactose intolerance are confusing, mainly because of biochemical individuality between and within different ethnic populations. ${ }^{6-811}$ Our analysis of the two polymorphisms suggests that heterozygotes can still have severe lactose intolerance. It has been reported that homozygous CC/GG have low lactase, those who are homozygous TT/AA are lactase persistent, and those who are heterozygous CT/GA are intermediate. ${ }^{1}$ We have found several TT/AA families with lactose intolerance, suggesting that this polymorphism is not the complete explanation of hypolactasia/lactase persistence. A further mechanism of loss of lactase is via endoplasmic reticulum stress, $^{29}$ and explains why loss of lactase persists after gut infections such as rotavirus.

When lactose reaches bacteria in the hypoxic large intestine, hydrogen and other metabolites are generated.

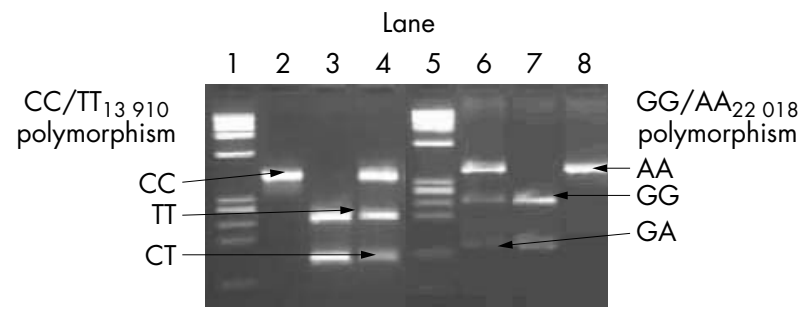

Figure 2 Lactase genotyping of polymorphisms $C / T_{13910}$ and $\mathrm{G} / \mathrm{A}_{22018}$ : a DNA test distinguishes between homozygous and heterozygous polymorphisms. Lactase genotyping for both lactase polymorphisms was carried out in our laboratory by PCR, HotStart 15 minutes at $95^{\circ} \mathrm{C}$ for one cycle, $93^{\circ} \mathrm{C} 40$ seconds, $62^{\circ} \mathrm{C} 1$ minute, $72^{\circ} \mathrm{C}$ for $1 \mathrm{~min} 40 \mathrm{~s}$. For 35 cycles, then 10 minutes at $72^{\circ} \mathrm{C}$. For the $C / T_{13910}$ polymorphism forward primer was GGACATACTAGAATTCACTGCAA and reverse primer was GGTTGAAGCGAAGATGGGACG and for the G/A $\mathrm{A}_{22018}$ the reverse primer was AGCTGGGACCACAAGCACCCGCCACCATGCGCGGCT AAT and the forward primer was CAGAGCTGTCTACACCAGTGGTA. PCR amplification products were incubated for three hours with BsmFI (three units) at $65^{\circ} \mathrm{C}$ for $\mathrm{C} / \mathrm{T}_{13910}$ and with BstUl (10 units) for the $\mathrm{G} / \mathrm{A}_{22018}$ polymorphism. The digested PCR amplification products were analysed on an ethidium bromide impregnated 3\% NuSieve GTG, 1\% agarose gel run for one hour at 120 volts in TAE buffer $\mathrm{pH} 8.0$ and visualised under UV light. Lane 1 and 5 are $\phi$ X-174 DNA/Hind III molecular weight markers. Lanes 2 and 7 shows the $C_{13910}$ (386 bp) and $\mathrm{GG}_{22018}$ (238 and $133 \mathrm{bp}$ ) homozygous lactase non-persistent genotypes respectively. Lanes 3 and 8 the $\Pi_{13910}$ (238 and 148 bp) and $\mathrm{AA}_{22018}(371 \mathrm{bp}$ ) homozygous lactase persistent genotypes

respectively. Lanes 4 and 6 are the $\mathrm{CT}_{13910}(386,238$ and $148 \mathrm{bp})$ and $\mathrm{GA}_{22018}(371,238$ and $133 \mathrm{bp}$ ) heterozygous lactase persistent genotypes respectively. The oligonucleotide primers contain an invariant cutting site engineered as a positive control, for $C / \mathrm{T}_{13910}$ a $35 \mathrm{bp}$ band and for $G / A_{22018}$ a 31 bp band (not shown on this gel). 


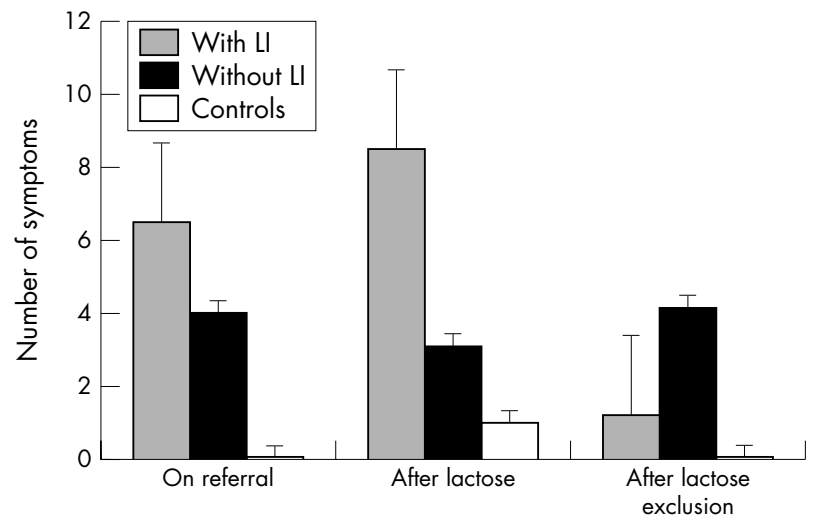

Figure 3 Symptoms before and after lactose. Data were based on a clinical study of 133 patients who were enrolled referrals to a food intolerance clinic. Of these, $85 \%$ came from gasteroenterologists, $15 \%$ from other physicians, and $10 \%$ from primary care. Ten cases refused the dietary management or did not return for follow up. Fifteen controls were people with no relevant medical history and who took a mixed diet. The ethnic origins were mainly white northern European (89\%). Patients were given $50 \mathrm{~g}$ oral lactose and the number of symptoms recorded (table 1) before, during and 12 weeks after the oral lactose load. Breath hydrogen was measured using a hand held monitor (Bedfont, UK) every 30 minutes for 12 hours. Patients were diagnosed as lactose intolerant as described in the text. $L I=$ lactose intolerance. A paired two tailed $t$ test $(95 \% \mathrm{Cl})$ showed that there was no significant difference between the symptoms recorded before and during the test; $p=0.051$ in patients diagnosed as lactose intolerant (with LI) and $p=0.60$ in patients diagnosed without lactose intolerance (without LI). In contrast the effect of removing lactose from the diet of those diagnosed with lactose intolerance was highly significant; $p=0.001$, but had no significant effect on symptoms in those diagnosed without lactose intolerance; $p=0.60$. Results represent the mean (SD).

These include potential toxic agents-acetaldehyde, acetoin, butan 2,3 diol, dimethyl glyoxal (diacetyl), ethanol, formate, methane, propan 1,3 diol, indoles, skatoles and short chain fatty acids $^{3} 1920$-as well as peptide and protein toxins. Lactose itself, and galactose, could be toxic if absorbed into the blood stream. These toxins act on ionic signalling pathways in the nervous system, heart and other muscles, and the immune system. Conventionally lactose intolerance causes diarrhoea via an osmotic mechanism. But we found in many patients diarrhoea persists for days, long after the lactose has gone. Thus it is probable that lactose induced diarrhoea is caused by a signalling mechanism analogous to cholera or enterotoxin. Bacterial putrifaction in the colon as a pathogen was first proposed 100 years ago by Metchnikoff. ${ }^{30}$ We have established an invertebrate model system, Daphnia pulex, to investigate this hypothesis. ${ }^{31}$

\section{THE PROBLEM OF LACTOSE IN FOOD}

Several studies have shown that patients considering themselves lactose intolerant could take one to two cups of milk $(240 \mathrm{ml}=11 \mathrm{~g}$ lactose $)$ during the day. ${ }^{32-36}$ Yogurt, ice cream, and cream can contain similar amounts to milk. The lactose content in many hard cheeses is quite low $(<\mathrm{lg}$ per teaspoon).${ }^{37}$ You would have to eat $1 \mathrm{~kg}$ of parmesan to take as much lactose as there is in a glass of milk. Thus a spoonful of parmesan on a pasta is unlikely to result in symptoms. Butter contains only traces of lactose. The threshold for lactose varies between people. Some can tolerate a glass of milk $(240 \mathrm{ml}=11 \mathrm{~g}$ lactose $)$, whereas others get symptoms with just 2-3 g lactose from a chocolate bar. ${ }^{35}$ We recommend that patients should experiment carefully with various foods to discover their lactose threshold. Some hypolactasics can, over months, adapt and increase their tolerance to milk. ${ }^{32}$ This occurs through the gut flora because mammalian lactase
Box 1 A cordon bleu meal for a person who is lactose intolerant

- Garlic mushrooms cooked in olive oil

- Coquilles St Jacques made with white wine and shallots, and coated with home made bread crumbs

- Lemon sorbet

- Grilled fillet steak, with a pepper and red wine sauce, flambéed in brandy with jacket potatoes or pommes Lyonaisse

- Salad with French dressing

- Fresh fruit salad or mouse au chocolate made with real dark chocolate and no cream

- Real black coffee or lemon tea, with petit fois made with real dark chocolate.

For ingredients and recipe details please email campbellak@ cf.ac.uk. Our complete recipe book will be available early in 2005.

cannot be induced by lactose, unlike its bacterial counterpart. Lactose can be reduced in dairy products by using $\beta$ galactosidase available in health food shops. Low lactose milk is available in supermarkets made by this method, but is quite sweet as it contains the galactose and glucose from the degraded lactose.

A problem for those sensitive to lactose, exacerbated over the past 5-10 years, is the presence of "hidden" lactose added to foods and drinks without being on the label. Lactose has about one sixth of the sweetness of sucrose. Unlike sucrose or glucose, lactose cannot be metabolised effectively by yeast. Thus lactose can be added to foods and drinks without causing a sickly taste, and without generating carbon dioxide or ethanol as a result of yeast metabolism. In the USA alone production of lactose in 1979 was about 50 million kg/ annum. $^{3}$ By 1999 this had increased fivefold. Now the estimated annual lactose production is 300 million $\mathrm{kg}$. This lactose is added to animal feeds and human foods. Lactose is used as a browning agent in bread, in bread and cake mixes, and is added to processed meats such as sausages and burgers. Lactose is even injected into some chicken meat. It is also added to some soft drinks and lagers. Some breakfast drinks, powders, and slimming products can contain as much lactose as milk, ${ }^{37}$ and lactose is often used in sauces supplied as powders to butchers and restaurants. We estimated the contents of one patient's weight reducing diet involved a daily intake of $100 \mathrm{~g}$ lactose, equivalent to $>2$ litres of milk, yet not stated on the label. We have thus set up a lactose HPLC assay for our patients.

We estimate that some 5-10 million people in the UK are hypolactasic. Indian restaurants often now use cream instead

Box 2 A disaster meal for someone who is lactose intolerant

- Cream of mushroom soup

- Pork à la crème with cauliflower cheese and creamed mash potatoes

- Salad dressed in mayonnaise made with cream,

- Full cheese board

- Crème bruleé

- Cappucinno coffee with Belgian chocolates 
of coconut milk. An important question is whether such changes to a westernised diet have any relevance to the unexplained epidemic in type 2 diabetes in the Asian population, or the high incidence of coronary artery disease in some parts of the world. Also questions need to be asked about the recommendation of milk to non-white Europeans. ${ }^{37}$ The lack of information regarding the lactose content of foods has important implications for the millions of people who are hypolactasic, and for ethnic groups (for example, orthodox Jews) who are forbidden to eat milk products with meat. Although most (89\%) of the patients in our study were white northern Europeans, a significant minority (11\%) were Asian or black African. As expected there was a higher percentage of CC/CT in the latter group. Thirty eight per cent of the CC group were Asian or black African (2 from 21 were south European), compared with only 1 of 41 patients in the CT group, with no non-white northern Europeans in the TT group. There was no obvious difference in symptoms of those who were lactose intolerant within these groups. However, in view of some reports that the conclusions from clinical trials may be affected by ethnic group, a full genetic profile of non-white northern Europeans is now required. Our data argue clearly that any epidemiological dietary study must take into account ethnic groups and lactose intolerance if the data are to be interpreted correctly. Coming off lactose does not prevent a patient enjoying eating and drinking to the full. A typical cordon bleu meal is shown in box 1 , with a disaster meal in box 2. A further problem is the presence of tri-saccharides and tetrasaccharides such as raffinose and stachyose found in many vegetables. ${ }^{3}$ These inhibit the uptake of glucose and galactose by the sodium dependent glucose transporter (SGLUT1). As a result sugars reach the bacteria in the large intestine leading to hydrogen and toxic bacterial metabolites, exacerbating symptoms in patients who are lactose intolerant.

There has been much debate about the recommended daily amount of calcium. One $250 \mathrm{ml}$ glass of milk contains about $300 \mathrm{mg}$ of calcium, one fifth of the daily requirement ( $1-2 \mathrm{~g})$. Some people who are lactose intolerant can obtain this by ingesting small amounts of milk throughout the day without exhibiting gut symptoms. ${ }^{35}$ Cheese is a good source of calcium, and a good portion of greens can supply $150 \mathrm{mg}$

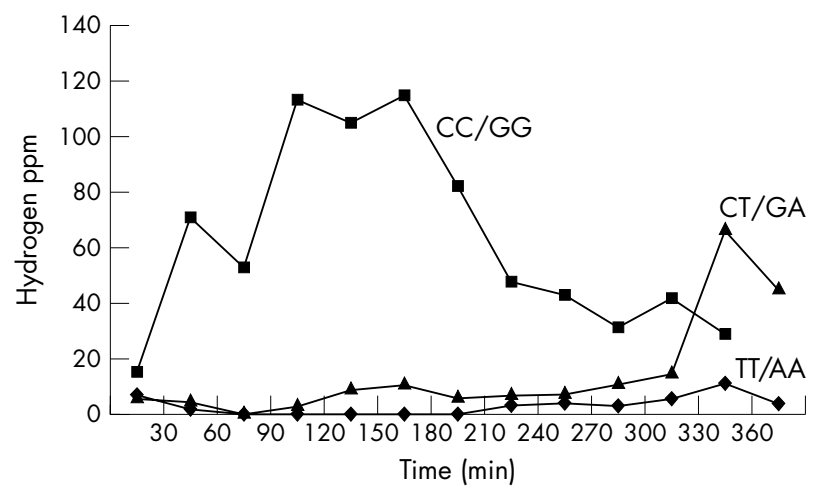

Figure 4 Effect of $50 \mathrm{~g}$ lactose on breath hydrogen in the three principal genetic groups. Breath hydrogen was measured every 30 minutes after ingesting $50 \mathrm{~g}$ oral lactose. The results represent an example of three adults all diagnosed clinically as lactose intolerant. Boxes represents CC/GG lactase non-persistent genotype, breath hydrogen $>20 \mathrm{ppm}$ above the nadir at 30 minutes and continues throughout the testing period. Triangles represent CT/GA heterozygous lactase persistent genotype showing a rise in breath hydrogen $>20 \mathrm{ppm}$ above the nadir after sampling above 300 minutes. Diamonds represent T/AA homozygous lactase persistent genotyped patient in which the breath hydrogen does not rise above 20 ppm throughout the testing period of 360 minutes. calcium. ${ }^{37}$ A serving of salmon or sardines contains up to $300 \mathrm{mg}$. Thus it is easily possible to take the necessary daily one to two grams calcium without milk. ${ }^{37}{ }^{38}$ (See also http://www.lactose.co.nz; http://www.lactose.co.uk; http:// www.parktonks.co.uk/milk_products; dailspace.dial.pipex. com/town/park/gfmll/).

Soya products with added calcium are readily available in supermarkets. In addition to the well known allergy to certain milk proteins, allergy to at least 16 proteins in soya milk has been found. ${ }^{39}$ This is rare. However, patients should be warned to look out for anything from a mild rash to a severe immune reaction to soya milk. If this occurs then they should be properly investigated and take care not to ingest any soya. Alternatives to soya are lactose reduced milk products, coconut milk, oat milk, or rice milk. There is no evidence of calcium deficiency in people eating a Chinese or Japanese diet with no lactose. Surprisingly calcium supplements can be cheaper than taking calcium via milk. ${ }^{37} 38$ Interestingly dairying is only $6000-8000$ years old..$^{40}$

\section{CONCLUSIONS}

It is now clear that lactose can cause a range of debilitating systemic symptoms, in addition to the well known gut

Box 3 Recommended new clinical management of patients investigated for lactose intolerance

(1) Patient referred for lactose tolerance test.

(2) Buccal sample for polymorphism analysis. A patient presenting with unexplained gut and/or systemic symptoms should first be tested for the two polymorphisms C/ $\mathrm{T}_{-13910}$ and $\mathrm{G} / \mathrm{A}_{-22018}$.

(a) If CC/GG or CC/GA immediate removal of all lactose from diet. If symptoms improve after one month diagnosis of lactose intolerance confirmed.

(b) If $C T / G A$ or $\Pi / A A$ carry out lactose tolerance test.

(3) New recommended lactose tolerance test:

(a) $50 \mathrm{~g} \mathrm{(1} \mathrm{g/} \mathrm{kg}$ for children) oral lactose.

(b) Record breath hydrogen every 30 minutes for three hours, then hourly up to six hours.

(c) Record all symptoms for $\mathbf{4 8}$ hours.

(d) If the breath test is positive, advice to change to a lactose free diet is given.

(e) Every patient should be followed up in 12 weeks for a definitive diagnosis. If the referred symptoms have significantly improved the diagnosis of lactose intolerance is made.

(f) If the breath test is negative, but there is a significant increase in symptoms after the lactose load, the patient should undergo a supervised trial to determine their lactose threshold.

(g) Family studies should be carried out to determine other affected people.

(h) Hypolactasia caused by infections such as Giardia or rotavirus should be investigated if there is no evidence of family history.

(4) Give advice on lactose free meals, and the danger of hidden lactose.

(5) Follow up in one year.

(6) Calcium and vitamin D status should be monitored, and advise on the use of probiotics. 
symptoms (table 1). Several patients complained of constipation since childhood rather than diarrhoea. The DNA test, coupled with a revised breath hydrogen test, argues for an important change in clinical practice (box 3). We recommend measuring breath hydrogen for six hours as this increases sensitivity from $40 \%$ to $60 \%$ (table 2 ). Symptoms should be assessed for up to 48 hours after $50 \mathrm{~g}$ lactose, using a self reported questionnaire. The lack of necessity for a lactose test in those who are CC/GG avoids severe reactions in these people. Only CT/GA or TT/AA patients should undergo the hydrogen breath test. The mean values (fig 4) hide the individuality of the time course from each patient.

It has been reported that the polymorphism analysis is not useful in managing IBD. ${ }^{41}$ But we show that it is required if the $80 \%$ of IBS with lactose intolerance are to be correctly identified. This had been missed previously because the patients had not been genetically or breath tested. Most patients had undergone endoscopic or barium studies, or both, with no abnormalities detected. Although the amount of lactose used by physicians around the world can vary from $1-2 \mathrm{~g} / \mathrm{kg}$ or $20-100 \mathrm{~g}, 25 \mathrm{~g}$ being sometimes used in the USA, the current recommended amount is $50 \mathrm{~g}$, or $1 \mathrm{~g} / \mathrm{kg}$ for children. Our results support the argument for a new trial, coupling the genetic test with breath hydrogen, to evaluate whether a lower dose than $50 \mathrm{~g}$ lactose is more accurate at diagnosing lactose intolerance. Our data show that the key issue is the beneficial effect of a true lactose free diet for at least one month. Fifty grams ( $1 \mathrm{~g} / \mathrm{kg}$ for children) is equivalent to 1 litre of cows' milk. This induced symptoms in some control subjects who had never reported any gut or systemic symptoms. Thus a study is needed to investigate whether a lower dose improves the predictive value in people who are TT/AA. Most of our patients were white northern European. The ethnic distribution of the C/T-13910 and G/A-22018 polymorphisms now needs to be examined, together with the incidence of systemic symptoms. There is a need to ensure adequate calcium intake, especially in children. Most studies assessing the true validity of a clinical intervention use a double blind, randomised, placebo controlled trial to remove bias. This is regarded as the "gold standard" for drug trials, reducing "placebo" effect artefacts. But the efficacy of this has been questioned. ${ }^{42-50}$ Some randomised studies on lactose intolerance have not used the correct criteria to establish whether the patient group, often small, really was lactose intolerant. ${ }^{35}$ Three key questions are:

- Is a double blind, randomised trial ethical?

- Does such an approach allow for multiple interventions?

- Has the validity of the "blinding" been properly evaluated?

Many of our patients suffer severe symptoms after the $50 \mathrm{~g}$ lactose load. Thus they refuse to participate in a double blind trial. It is unethical to put them through this unnecessary suffering. We have found it impossible to find a substitute to lactose that prevents the subject guessing whether they are taking lactose or not. Our study was a clinical one, based on rigorous clinical criteria. The DNA analysis was undertaken blind, and precautions were taken to minimise bias in the analysis of symptoms and breath hydrogen. All clinicians have patients who unknowingly improve as a result of a placebo effect. In our study we now have over 300 patients who have shown a dramatic improvement in both gut and systemic symptoms, sustained over more than one year. In patients diagnosed with lactose intolerance the average number of symptoms dropped from nine to one (fig 3), when they excluded lactose from their diet. This was highly significant $(\mathrm{p}<0.001)$. This cannot be explained by a placebo effect. The only time symptoms returned was when the patient unknowingly ingested food containing "hidden" lactose. In contrast excluding lactose from the diet had no significant effect $(p=0.6)$ on the symptoms of patients not diagnosed as having lactose intolerance.

The data reported here have important implications for the management of IBS, chronic fatigue, arthritis, and for reducing GP visits and drug costs. They also highlight the key problem of defining when and why a patient crosses the rubicon that determines illness compared with health. ${ }^{51}$ The puzzle of what determines the loss of lactase on weaning remains. The possibility that homeobox genes associated with the development of deciduous teeth are involved in loss of lactase after weaning should now be investigated..$^{52}$ Our findings also explain the mystery illness that afflicted Charles Darwin for 40 years. ${ }^{53}$

\section{ACKNOWLEDGEMENTS}

We thank Suzanne Watkins, specialist nurse for assistance with lactose tolerance testing.

\section{Authors' affiliations}

S B Matthews, J P Waud, Department of Medical Biochemistry and Immunology, Llandough Hospital, Cardiff and Vale NHS Trust, Penarth, Vale of Glamorgan, UK

A G Roberts, Department of Medical Biochemistry and Immunology, Cardiff and Vale NHS Trust, Cardiff, UK

A K Campbell, Department of Medical Biochemistry and Immunology, Wales College of Medicine, Cardiff University, Cardiff, UK

Funding: we thank the Department of Medical Biochemistry and Immunology for financial support.

Competing interests: none.

This study was approved by the appropriate ethics committee.

\section{REFERENCES}

1 Enattah NS, Sahi T, Savilahti E, et al. Identification of a variant associated with adult-type hypolactasia. Nat Genet 2002;30:233-7.

2 Brostoff J, Gamlin L. The complete guide to food allergy and intolerance. London: Bloomsbury, 1989.

3 Campbell AK, Matthews SB. Lactose intolerance and the MATHS syndrome: what are the and how can I cope. Pembrokeshire: Welston Press, 2001.

4 Kretchmer N. Memorial lecture: lactose and lactase-a historical perspective. Gastroenterology 1971;61:805-13.

5 Carper S. Milk is not for everybody. New York: Facts On File, 1995.

6 Flatz G. Genetics of lactose digestion in humans. Adv Hum Genet 1987; 16:1-77

7 Sahi T. Genetics and epidemiology of adult-type hypolactasia Scand J Gastroenterol 1994;202(suppl 29):7-20.

8 Swallow DM. Genetics of lactase persistence and lactose intolerance. Annu Rev Genet 2003;37:197-219.

9 Olds LC, Sibley E. Lactase persistence DNA variant enhances lactase promoter activity in vitro: functional role as a cis regulatory element. Hum Mol Genet 2003; 12:2333-20.

10 Cuatrecasas P, Lockwood DH, Caldwell JR. Lactase deficiency in the adult. A common occurrence. Lancet 1965;i:14-18.

11 Cook GC, Kajubi SK. Tribal incidence of lactase deficiency in Uganda. Lancet 1966;i:725-30.

12 Fauchi AS, Braunwald E, Isselbacher KJ, et al. Disorders of the gastrointestinal system. In: Harrison's principles of internal medicine. 14th ed. New York: McGraw Hill, 1998:631.

13 Srinivasan D, Minocha A. When to suspect lactose in tolerance. Symptomatic, ethnic, and laboratory clues. Postgrad Med 1998;104:109-23.

14 Bohmer CJM, Tuynman HAR. The effect of a lactose-restricted diet in patients with a positive lactose tolerance test, earlier diagnosed as irritable bowel syndrome: a 5-year follow-up study. Eur J Gastroenterol Hepatol 2001;13:941-4.

15 Jarvis KK, Miller GD. Overcoming the barrier of lactose intolerance to reduce health disparities. J Natl Med Assoc 2002;94:55-66.

16 Grimbacher B, Peters T, Peter H-H. Lactose-intolerance may induce severe chronic eczema. Int Arch Allergy Immunol 1997;113:516-18.

17 Treuder R, Tebbe B, Steinhoff $M$, et al. Familial aquagenic urticaria associated with familial lactose intolerance. J Am Acad Dermatol 2003;47:611-13.

18 Matthews SB, Campbell AK. When sugar is not so sweet. Lancet 2000;355:1309.

19 Matthews SB, Campbell AK. Neuromuscular symptoms associated with lactose intolerance. Lancet 2000;356:51 1.

20 Matthews SB, Campbell AK. Lactose intolerance in the young: a new perspective. Welsh Paediatric J 2004;20:56-66

21 Joseph F, Rosenberg AJ. Breath hydrogen testing: diseased versus normal patients. J Pediatr Gasterenterol Nutr 1988;7:787-91. 
22 Duncan A, Hill PG. A UK survey of laboratory-based gastrointestinal investigations. Ann Clin Biochem 2001;35:492-503.

23 Obermayer-Pietsch BM, Bonelli CM, Walter DE, et al. Genetic predisposition for adult lactose intolerance and relation to diet, bone density, and bone fractures. J Bone Miner Res 2004; 19:42-7.

24 Mantei N, Villa M, Enzler T, et al. Complete primary structure of human and rabbit lactase-phlorizin hydrolase: implications for biosynthesis, membrane anchoring and evolution of the enzyme. EMBO J 1988;7:2705-13.

25 Boll W, Wagner P, Mantei N. Structure of the chromosomal gene and cDNAs coding for lactase-phlorizin hydrolase in humans and adult-type hypolactasia or persistence of lactase. Am J Hum Genet 1991;48:889-902.

26 Wuthrich M, Grunberg J, Hahn D, et al. Proteolytic processing of human lactase-phlorizin hydrolase is a two-step event: identification of the cleavage sites. Arch Biochem Biophys 1996;336:27-34.

27 Mackey AD, Henderson GN, Gregory JF. Enzymatic hydrolysis of pyridoxine5 -beta-D-glucoside is catalysed by intestinal lactase-phlorizin hydrolase. J Biol Chem 2002;277:26858-64.

28 Fowler AV, Zabin I. Amino acid sequence of $\beta$-galactosidase XI. Peptide ordering procedures and the complete sequence. J Biol Chem 1978;252:5521-5.

29 Llewelyn DH, Roderick L, Sheik N, et al. Calcium stress induces calreticulin gene expression. Biochem J 1996;318:400-10.

30 Metchnikoff E. The nature of man. Studies on optimistic philosophy. (English translation edited by P Charles Mitchell). New York: G P Putnam, 1908:73.

31 Campbell AK, Wann KT, Matthews SB. Lactose causes heart arrhythmia in the water flea Daphnia pulex. Comp Biochem Physiol B 2004;139:225-34.

32 Hertzler SR, Huynh B, Savaiano DA. How much lactose is 'low' lactose. J Am Diet Assoc 1996;96:243-6.

33 Pribila BA, Hertzler SR, Martin BR, et al. Improved lactose digestion in intolerance among African-American adolescent girls fed a dairy rich diet. J Am Diet Assoc 2000; 110:826-32.

34 Shrimshaw HS, Murray EB. The acceptability of milk and milk products in populations with high prevalence of lactose intolerance. Am J Clin Nutr 1998:48:1083-159.

35 Suarez FL, Savaiano DA, Arbisi P, et al. Tolerance to the daily ingestion of two cups of milk by individuals claiming lactose intolerance. Am J Clin Nutr 1997:65:1502-6.

36 McCray S. Lactose intolerance: considerations for the clinician. Practical Gasteroenterology 2003;Feb:21-39.
37 Moore BJ. Dairy foods: are they politically correct. Nutrition Today 2003;38:82-90.

38 Suarez FL, Adshead J, Furne JK, et al. Lactose maldigestion is not an impediment to the intake of $1500 \mathrm{mg}$ calcium daily as dairy products. Am J Clin Nutr 1998;68:1118-22.

39 Cordle CT. Soy protein allergy: incidence and relative sensitivity. J Nutr 2004; 134: 1213-19S.

40 Dudd SN, Evershed RP. Direct demonstration of milk as an element of archeological economies. Science 1998;282:1478-81.

41 Buning C, Ockenga J, Kruger S, et al. The C/C-13910 and G/G-2028 genotypes for adult-type hypolactasia are not associated with inflammatory bowel disease. Scand J Gasteroenterol 2003;38:538-42.

42 Vickers AJ, deCraen AJ. Why use placebos in clinical trials? A narrative review of the methodological literature. J Clin Epidemiol 2000;53:157-61.

43 Cleophas TJ, Zwinderman AH. Limitations of randomized clinical trials. Proposed alternative designs. Clin Chem Lab Med 2000;38:1217-23.

44 Kaptchuk TJ. The double-blind, randomized, placebo-controlled trial: gold standard or golden calf? J Clin Epidemiol 2001;54:541-9.

45 Montori VM, Bhandari M, Devereaux PJ, et al. In the dark: the reporting of blinding status in randomized controlled trials. J Clin Epidemiol 2002;55:787-90.

46 Moayyedi P. Bringing science to the art of diagnosis. Gut 2004;53:627-8.

47 Vlieg-Boerstra BJ, Biileveld CMA, van der Heidee S, et al. Development and validation of challenge materials for double-blind, placebo-controlled food challenges to children. J Allergy Clin Immunol 2004;113:341-6.

48 Bang H, Ni L, Davis CE. Assessment of blinding in clinical trials. Control Clin Trials 2004;25:143-56.

49 Fergusson D, Glass KC, Waring D, et al. Turning a blind eye: the success of blinding reported in a random sample of randomised, placebo controlled trials. BMJ 2004;328:432.

50 Puzynski S. Placebo in the investigation of psychotropic drugs, especially antidepressant. Sci Eng Ethics 2004;10:135-42.

51 Campbell AK. Rubicon: the fifth dimension of biology. London: Duckworth, 1994.

52 Sharpe PT. Homeobox genes in initiation and shape of teeth during development in mammalian embryos. In: Teaford MF, Smith MM, Fergusin, FW, eds. Development, function and evolution of teeth. Cambridge: Cambridge University Press, 2000:3-12.

53 Campbell AK, Matthews SB. Darwin's illness revealed. Postgrad Med J (in press). 